\title{
Eetilised valikud COVID-19 pandeemia tingimustes ${ }^{1}$
}

\author{
Margit Sutrop \\ Tartu Ülikooli praktilise filosoofia professor, \\ eetikakeskuse juhataja \\ margit.sutrop@ut.ee \\ Kadri Simm \\ Tartu Ülikooli praktilise filosoofia kaasprofessor \\ kadri.simm@ut.ee
}

\begin{abstract}
Teesid: COVID-19 pandeemia on toonud kaasa keerulisi eetilisi valikuid, sest põrkuvad olulised väärtused: elu ja majanduslik heaolu; individuaalne vabadus ja tervis; inimeste vaba liikumine ning rahva tervis; üksikisiku enesemääramisõigus ning solidaarsus. Liikumispiirangute kehtestamine, vaktsineerimise korraldamine ning piiratud tervishoiuressursside jagamine tekitavad lahkarvamusi kõigis demokraatlikes ühiskondades. Vastuvõetud poliitikad ning väljatöötatud juhtnöörid näitavad, et eri maad lähtuvad erinevatest eetilistest raamistikest, milles üks seab esikohale isikuvabadused, teine aga ühishüve. COVID-19 pandeemia kõige raskemad eetilised valikud on seotud intensiivravivoodite, haiglakohtade ning hingamisaparaatide jaotamisega olukorras, kus ressursside nappuse tõttu ei ole kõiki abivajajaid võimalik aidata.

Artikkel iseloomustab COVID-19 pandeemia raames enim vaidlusi tekitanud eetilisi küsimusi, keskendudes Eesti haiglate jaoks koostatud kliinilise eetika alastele juhtnööridele. Artikkel annab ülevaate juhtnööride koostamise protsessist, toimunud aruteludest ja õppetundidest tuleviku jaoks, näidates ka, kuidas Eesti dokument paigutub rahvusvahelisse konteksti.
\end{abstract}

Märksõnad: COVID-19 pandeemia, eetika juhtnöörid, eetilised valikud, kliinilise eetika alased soovitused haiglatele, piiratud tervishoiuressurssid, vaktsineerimispass, väärtused

\section{Põrkuvad väärtused}

COVID-19 pandeemia on toonud kaasa keerulisi eetilisi valikuid, sest põrkuvad olulised väärtused: elu ja majanduslik heaolu; individuaalne vabadus ja tervis; inimeste vaba liikumine ning rahva tervis; üksikisiku enesemääramisõigus ja solidaarsus. Kõrge nakkuskordaja on valitsust sundinud inimeste liikumist piirama, et peatada nakkuse kiire levik, päästa elusid ja säilitada tervishoiusüsteemi toimepidevus. See tähendab aga ka seda, et piiratakse inimeste individuaalseid õigusi. Elu ja tervis seatakse kõrgemale vabadusest. Samal ajal 
võivad paljude inimeste vaimne ja füüsiline tervis kehtestatud piirangute tõttu halveneda ning kannatada teiste haiguste ravi. Haridusasutuste viimine kaugõppele, kultuuri-, toitlustusasutuste ning kaubandusasutuste ja turismiettevõtete tegevuse ajutine peatamine on andnud valusa löögi ettevõtlusele ja vähendanud kõigi ühiskonnaliikmete heaolu. Omakorda, kui piiranguid ei rakendataks või rakendataks vähe, on suur oht, et pandeemia üle kaotataks kontroll ja kahjud nii inimeludele kui ka majandusele oleksid veelgi suuremad, nagu on näidanud Hiina, Itaalia ja India kogemus. Häid valikuid ei ole.

Väärtuste põrkumist näeme ka vaktsineerimise puhul. Arutletakse selle üle, kas vaktsineerimist saab muuta kohustuslikuks. On selge, et kehalist puutumatust tuleb austada ja kedagi vägisi vaktsineerida ei saa. Samas on ameteid, kus vaktsineerimine peaks käima kutse-eetika juurde ning mittekahjustamise printsiip on teatavasti üks meditsiini vanimaid eetilisi alustalasid. Tervishoiutöötaja seab vaktsiinist keeldudes ohtu mitte ainult oma tervise ja elu, vaid ka patsientide oma. Ka õpetaja, kes vastutab laste tervise eest, seab vaktsineerimisest keeldumisega ohtu oma kasvandikud ja nende vanemad. Sellises olukorras peaks vastutus teiste ees kaaluma üles isikliku otsustusvabaduse.

Vaktsineerimispassi kasutuselevõtt sõltub mitte ainult tehnilisest võimekusest, vaid ka sellest, kuidas me lahendame eetilised küsimused. Ühelt poolt annab see võimaluse ühiskonda suuremal määral avada: need, kes on vaktsineeritud, haiguse läbi põdenud või teinud negatiivse testi, ei ole nakkusohtlikud. Vaktsineerimispassi kasutuselevõtt muudab reisimise turvalisemaks ja võimaldab korraldada suurüritusi ning avada spordiklubid või restoranid neile, kel tõend ette näidata.

Samas tähendab see, et teatud hüved on kättesaadavad vaid piiratud arvule inimestele. Kui vaktsiinipassi saamine sõltuks üksnes inimese enda otsusest lasta end vaktsineerida, võiks selle kasutuselevõtt olla väga hea viis motiveerida inimesi kaitsepookima. Ent kuni vaktsiine pole piisavalt ja neid ei jagu kõigile, suurendab nende kasutuselevõtt ebavõrdsust - inimesed, kellel pole vaktsiinidele juurdepääsu, jäävad ilma ka teistest hüvedest.

Võib argumenteerida ka nii, et neilt, kes pole vaktsineeritud, ei võeta midagi ära, sest sellised hüved nagu reisimine või spordi- ja kultuuriüritustel osalemine ei olnud ka seni piirangute tõttu võimalikud. Vahe on lihtsalt selles, et enne olid need kõigile keelatud, nüüd on vaktsineeritutele avatud. Kui aga vähemalt osa ühiskonnast saab reisida, käia kontsertidel, teatris, spordivõistlustel, restoranides ja klubides, annab see inimestele tööd ja ettevõtted jäävad ellu. Pikemas perspektiivis võidavad sellest kõik.

COVID-19 pandeemia kõige raskemad eetilised valikud on seotud intensiivravivoodite, haiglakohtade ning hingamisaparaatide jaotamisega olukorras, kus ressursside nappuse tõttu ei ole kõiki abivajajaid võimalik aidata. Taolises 
olukorras tehtavad valikud on oma olemuselt eetilised dilemmad, kus valida on vaid halva ja veel halvema lahenduse vahel. Tegemist on traagilise olukorraga: ükskõik mida ka ei otsustataks, kaasneb arstide iga otsusega kahetsus, sest polnud võimalik teha kõike, mida oleks pidanud tegema. Samas võib kahetsusest hoolimata olla tegemist õige otsusega, kui iga muu otsus, sh otsus mitte midagi teha, oleks olnud veel halvem, sest oleks kaasa toonud suurema kahju.

On selge, et niisugune moraalses mõttes väljapääsmatu olukord paneb tervishoiutöötajad suure psüühilise pinge alla. Selleks, et tagada otsuste läbipaistvus ja objektiivsus ning võtta klinitsistidelt otsustamiskoormat vähemaks, on koostöös bioeetikutega välja töötatud eetilised juhtnöörid triaažiotsuste tegemiseks ning piiratud tervishoiuressursside jagamiseks.

2020. aasta kevad tõi kaasa tõelise eetikabuumi (Häyry 2020). Aprilliks 2020 oli enamik Euroopa riike valmis saanud sellealased eetika juhtnöörid. Mõned on küsinud, kas meditsiinitöötajad tegelikult vajasid selliseid juhiseid, kuna erakorralise meditsiini arstid kogevad pidevalt kriitilisi olukordi ning olemasolevaid kliinilisi juhiseid saab rakendada ka uue pandeemia korral (McCullough 2020). Tõepoolest on koostatud suurel hulgal juhiseid rahvusvahelisel, riiklikul, erialasel ja kohalikul tasandil ning selle tulemuseks on võimalikud ebakõlad, palju dubleerimist ja kliiniliste otsuste tegijatele suunatud informatsiooni üldine üleküllus (Huxtable 2020a).

Kuid mitte kõik riigid ei olnud enne kirja pannud intensiivravi osutamiseks kliinilisi juhiseid, mida saaks kasutada ka erakorralistes piiratud ressursside tingimustes. Näiteks tunnistas Eesti Anestesioloogide Selts COVID-19 pandeemia ajal, et on vaja sõnastada täpsed triaažireeglid intensiivraviüksuste jaoks. Suulise teate järgi ${ }^{2}$ hindasid anestesioloogid soovituste koostamiseks tehtud tööd ja tervitasid täiendavat tuge mõtlemaks läbi kriisiolukorras tehtavate raskete otsuste eetilisi aluseid.

Eesti haiglatele juhtnööride koostamise võtsid enda peale Põhja-Eesti Regionaalhaigla eetikanõukogu, Tartu Ülikooli eetikakeskus ja Tartu Ülikooli Kliinikumi eetikakomitee. Põhjaliku teadustöö ja intensiivsete arutelude tulemusena valmis dokument "Kliinilise eetika alased soovitused Eesti haiglatele piiratud ressursside jaotamiseks COVID-19 pandeemia tingimustes" (Ammer \& Elmet jt 2020), mis sõnastas 12 soovitust piiratud tervishoiuressursside jaotamiseks kriisioludes.

Järgnevas kirjeldame Eesti haiglatele koostatud soovituste sõnastamise protsessi piiratud tervishoiuressursside jaotamiseks COVID-19 pandeemia ajal, sealhulgas osaliste kaasamist, seoseid võrreldavate rahvusvaheliste dokumentidega, peamisi vaidlusi ja tulevikuks saadud õppetunde. 


\section{Sündmuste kronoloogia ja osalised}

Reageerides koroonaviiruse levikule Eestis kuulutas Eesti valitsus 12. märtsil 2020 välja eriolukorra. Esialgu pidi eriolukord kehtima 1. maini 2020, kuid 24. aprillil pikendati seda viiruse jätkuva leviku tõttu 17. maini.

Eesti haiglatele soovituste koostamise tervishoiuressursside jaotamiseks COVID-19 pandeemia ajal algatas Põhja-Eesti Regionaalhaigla (PERH) kriisijuhtimise komisjon. Eesti Terviseamet oli 24. märtsil määranud kaks suurimat haiglat, PERHi Tallinnas ja Tartu Ülikooli Kliinikumi (TÜK) Tartus vastutavaks COVID-19 ravi eest kõikides haiglates vastavalt Eesti põhja- ja lõunaregioonis. PERHi kriisijuhtimise komisjon palus haigla eetikanõukogul töötada välja juhised tervishoiuressursside jaotamiseks COVID-19 pandeemia ajal. PERHi eetikanõukogu tuli kokku 25. märtsil ning arutas selleks hetkeks juba olemasolevaid Itaalia juhiseid (Vergano \& Bertolini et al. 2020) ja teadusartikleid (Rosenbaum 2020; Ezekiel \& Persad et al. 2020), mis käsitlesid tervishoiuressursside õiglast jaotamist olukorras, kus on suur vajadus intensiivravikohtade ja hingamisaparaatide järele. Sel päeval oli surnud Eesti esimene COVID-19 diagnoosiga patsient ja diagnoositud oli 404 juhtumit; 28 inimest oli haiglas ja seitse vajas intensiivravi. Halvim stsenaarium nägi ette intensiivravi üksuste ülekoormust kogu riigis 2-3 nädala jooksul. Valitsuse nõustamiseks loodi ad hoc COVID-19 teadusnõukoda, mis 24. märtsil hoiatas, et kahe nädalaga võib intensiivravi vajada 100 patsienti, kolme nädalaga isegi kokku 200-300 patsienti. Hinnati, et kogu riigis on maksimaalne võimekus 130 hingamisaparaadiga intensiivravikohta (veel 75 hingamisaparaati oli olemas, kuid puudus piisavalt väljaõpetatud personal). Sel hetkel oli Eestis 3. taseme intensiivravi kohtadest hõivatud $49 \%$.

Pärast esimese mustandi arutamist PERHi eetikanõukogu erakorralisel koosolekul (25. märtsil) otsustati, et piirkondliku dokumendi asemel, mis puudutaks ainult PERHi koordineeritavaid Põhja-Eesti haiglaid, oleks parem suunata soovitused kõikidele Eesti haiglatele. Seepärast saadeti kutse Tartu Ülikooli Kliinikumile, mis vastutas kõigi Lõuna-Eesti haiglate eest, et valmistada ette ühine dokument. Kui mõlema haigla kriisikomisjoni juhid, professor Peep Talving (PERHi ülemarst) ja professor Joel Starkopf (TÜKi anestesioloogia ja intensiivravi kliiniku juhataja) leppisid kokku, et tuleks luua ühine dokument, sai protsessi teiseks partneriks Tartu Ülikooli Kliinikumi kliinilise eetika komitee. Kolmas partner, kes aitas dokumenti koostada, oli interdistsiplinaarne Tartu Ülikooli eetikakeskus, kes asus koostöös mõnede meditsiini, eetika ja õiguse ekspertidega väljastpoolt uurima muid rahvusvahelisi dokumente ning valmistama ette soovituste eetilist ja õiguslikku analüüsi. Märtsi viimasel nädalal kirjutasid kummagi haigla eetikakomitee ja eetikakeskuse liikmed 
dokumendi esimese mustandi, mis paluti läbi vaadata meditsiini, bioeetika ja õiguse ekspertidel ning seejärel muudeti vastavalt nende soovitustele. Seejärel töötati mustandiga Google Docsi keskkonnas, tunde kestnud Skype’i kõnede abil leiti ühised sõnastused. Kliinilise meditsiini alase analüüsi eest vastutasid dr Jaan Tepp ja dr Kristo Erikson PERHist, õigusliku analüüsi tegi prof Jaan Ginter (TÜ) ning eetilise analüüsi prof Margit Sutrop (TÜ) ja kaasprofessor Kadri Simm (TÜ). Protsessi koordineeris Andra Migur PERHist.

Soovituste lõplik versioon kooskõlastati terviseameti ja vabariigi presidendiga. Juhiste olemasolust ja Eesti haiglatele jagamisest teavitav pressiteade avaldati PERHi kodulehel 6. aprillil 2020 ja Postimehes avaldatud artiklis selgitati eetilist lähenemist (Sutrop 2020). Pressiteates rõhutati, et neid juhiseid tuleks võtta ennetava meetmena, mida loodetavasti ei lähe vaja, kuid mis tagaksid olukorra halvenedes, et arstid teavad, millele oma otsustes tugineda.

Meediakajastus oli üsna elav (teemat märgiti meedias umbes 20 korral); soovitusi mainiti kõikides päevalehtedes ning mitmes raadio- ja telekanalis. 13. aprillil arutas soovitusi riigikogu sotsiaalkomisjon veebiistungil. Dr Kristo Erikson (PERH) ja prof Margit Sutrop (TÜ) selgitasid soovituste koostamise protsessi ning vastasid riigikogu liikmete ja sotsiaalministeeriumi esindajate küsimustele. Kuigi kahe suurima haigla eetikakomitee ja eetikakeskuse ühist algatust hinnati ja peeti koostöö heaks näiteks, heitsid sotsiaalministeeriumi esindajad ette, et neid ei olnud protsessi kaasatud. Samuti peeti küsitavaks soovituste ajastust, kuna selleks ajaks kui dokument avaldati, oli juba selge, et valitsuse kehtestatud piiravad meetmed viiruse leviku kontrollimiseks on olnud tõhusad ja et haiglaravi, eriti intensiivravi vajavate patsientide arv on kardetust palju väiksem (6. aprillil 2020 oli Eestis 1108 kinnitatud juhtumit, 129 inimest oli haiglas, nendest 14 intensiivravil). 2020. aasta kevadel oli kõige rohkem juhitaval hingamisel patsiente korraga 20 (3. aprillil) ja kõige rohkem inimesi haiglas 157 (12. aprillil).

Haiglate ülekoormus tekkis aasta hiljem, 2021. aasta kevadel (tipuks 4. aprillil 2021. aastal 725 inimest haiglas, 31. märtsil intensiivravis 76 inimest). 2021. aasta esimestel kuudel oli tervishoiusüsteem toimevõime kaotamisele päris lähedal. Saime siiski hakkama: haiglad tegid tihedat koostööd ning jaotasid haigeid eri haiglate vahel. Sügav tänu ja kiitus meie meedikutele! Kui tekkis reaalne oht, et meditsiinisüsteem kukub kokku, kehtestati piirangud, nakatumist vähendati ja nakkuskordaja langes.

Kui palju COVID-19sse haigestumisi ja surmasid liikumispiirangutega ära on hoitud, ei tea täpselt keegi. Ei teata ka seda, kui palju on piirangute nähtamatuid või isegi nähtavaid ohvreid. Teadusnõukoda annab valitsusele teadmispõhist nõu viiruse leviku ja tervishoiusüsteemi toimepidevuse kohta. Ent piirangute kehtestamise või leevendamise puhul tuleks kaaluda ka teisi 
väärtusi. "Peame järgima eetikat, mitte lihtsalt teadust," kirjutavad Suurbritannia bioeetikud (Huxtable 2020b).

\section{Moraalne kompass arstidele raskete otsuste tegemisel}

Eesti haiglate juhtnööride loomiseks uuriti tähelepanelikult lisaks Itaalia juhistele (Vergano \& Bertolini et al. 2020) Austria (Österreichische... 2020), Belgia (Meyfroidt ja Vlieghe et al. 2020), Saksa (DIVI 2020) ja Šveitsi Akadeemia (Swiss... 2020) juhiseid. Vaatasime ka Suurbritannia rahvusliku tervishoiu ja hoolduse instituudi COVID-19 kiirjuhiseid (NICE 2020), Briti meditsiiniühingu (BMA 2020) ja USA Hastingsi keskuse juhiseid asutuste eetikateenistustele COVID-19 reageerimiseks (Berlinger \& Wynia et al. 2020). Eetilised raamistikud olid mitmesugused, kuigi sageli kasutati laias laastus utilitaristlikku lähenemist, mis on katastroofibioeetikas tavaks kujunenud. Kriisiolukorras nihkub fookus tavameditsiini patsiendikeskselt lähenemiselt kogukonnakesksele lähenemisele, mis seab esiplaanile kollektiivsed väärtused nagu solidaarsus, vastastikkus ja turvalisus (Sutrop 2011a; Sutrop 2011b). Teistsugust vaatenurka pooldas Saksa eetikanõukogu arvamus (Deutscher Ethikrat 2020), mis pidas olulisimaks õiguste-põhist lähenemist ja erines sellega märgatavalt teistest samalaadsetest dokumentidest, milles kasutati kommunitaarsemaid ja ühishüve põhiseid põhjendusi. Saksa eetikanõukogu arvamust (2020) on kiidetud vastuväidete eest utilitaristlikule põhimõttele, mille järgi on eesmärk päästa maksimaalselt elusid ning eluaastaid, samas kui õiguste-põhises eetikas on oluline hoiduda mis tahes diskrimineerimisest ja austada igaühe õigust ravile (Lübbe 2020). Kuid niisugust lähenemist on kritiseeritud selle eest, et see läheb intuitsiooniga vastuollu (ei saa anda võrdset kaalu patsiendile, kellel on elada jäänud päevi, ja patsiendile, kes võiks elada veel 50 aastat!), ja selle eest, et nõnda jäetakse kliiniliste otsuste tegijad juhisteta, kuidas toimida kahe vastandliku kohustuse korral. Nii juhtus eetiliste dilemmade puhul, mille ees seisid arstid Hiinas, Itaalias ja Hispaanias, olles olukorras, kus ei jätkunud intensiivravikohti kõigile, kes neid vajasid, ja arstidel tuli otsustada, kumb kohustus on tugevam: kohustus aidata või kohustus mitte kahjustada.

Võttes hingamisaparaadi patsiendilt, kes saabus varem, kuid kelle prognoos on halvem, ja andes selle patsiendile, kelle on parem meditsiiniline prognoos (kes vajab tõenäoliselt hingamisaparaati vähem päevi, võimaldades sellega aidata suuremat hulka patsiente), võib päästa rohkem elusid, kuid rikkuda kohustust mitte kahjustada. Ükskõik kumma valiku arst tegi, jättis ta tegemata teo, mida tal oli samuti põhjust teha. Pange tähele, et isegi kui ta ei suutnud otsustada, oli dilemma vältimine samuti valik, mis viis samade tulemusteni 
kui esimene valik - aidata patsienti, kes juhtus saabuma varem. Mida arst ka ei teinud, tulemuseks oli tõenäoliselt kahetsus, isegi kui ta mõistis ratsionaalselt, et ta toimis õigesti.

Sellised valikud nõuavad moraalse arutlemise võimet, et kaaluda erinevaid väärtusi, anda eelis teatud olulistele eetilistele printsiipidele teiste ees ja teha lõpuks eetiliselt põhjendatud valik. Need on komplekssed oskused, kuid neid saab õppida (Simm 2020). Eestis on TÜ eetikakeskus viimase kümne aasta jooksul koolitanud sadu meditsiinitöötajaid arstide väärtuste mängu abil (Arstide väärtuste mäng), mis keskendub eetilise arutlemise oskuste arendamisele moraalsete dilemmade korral. Haiglatele soovituste kirjutamise ajal mõistsid eetikakomiteede liikmed, et haigla ees seisavad eetilised dilemmad on sarnased nendega, mida nad mäletasid väärtuste mängu koolituselt, seega tundsid nad end üsna valmis olevat sõnastama juhiseid eetiliste dilemmadega toimetulemiseks erakorralistes piiratud ressursside tingimustes.

Kuid nagu näitasid hiljem arutelud haiglates, uskusid paljud Eesti arstid, et neil oleks olnud väga raske juhiste järgi toimida, sest arste on õpetatud toimima Hippokratese vande järgi, mille kohaselt arst peab andma elupäästvat ravi. Seega, kui arst on piiratud ressursside tingimustes surve all lõpetada patsiendi aktiivne ravi, sest ressursse saaks tõhusamalt kasutada mõne teise patsiendi jaoks, võib arst tajuda olukorda ebaeetilisena ning vastuolus Hippokratese vande väärtuste ja põhimõtetega. Lisaks sellele tajusid nad ka karistuse ohtu, sest kriminaalseaduse järgi on abi andmata jätmine karistatav. Selliseid olukordi ette nähes teatas üks meditsiiniõigusele spetsialiseerunud advokaat, kohe kui soovitused avaldati, et ta on valmis isiklikult ja tasuta kaitsma kohtus meditsiinitöötajaid, kes juhiseid järgisid (Nõmper 2020).

\section{Mis iseloomustab Eesti soovitusi?}

Eesti juhised rõhutavad, et neli tuntud meditsiinieetika printsiipi - õiglus, heategemine, mittekahjustamine ja autonoomia - kehtivad ka kriisiolukorras, kuid nende osakaal on teistsugune. Tavalises olukorras on kliiniline meditsiin patsiendikeskne: meditsiinitöötajate kohus on hoolitseda iga patsiendi heaolu ja tervise eest (heategemise printsiip), vältida kahju tekitamist (mittekahjustamise printsiip), võtta arvesse patsiendi isiklikke eelistusi ja väärtusi (autonoomia ja inimväärikuse austamine) ning kohelda kõiki patsiente võrdselt, hoidudes kedagi diskrimineerimast tema vanuse, soo, vaimse või füüsilise erivajaduse tõttu (õigluse printsiip).

Eesti juhised rõhutavad, et vanus ei ole intensiivravi puudutavate otsuste tegemisel otsene kriteerium. Peamised kriteeriumid intensiivravi alustamiseks 
või jätkamiseks peaksid olema ravi õnnestumise meditsiiniline väljavaade ning tulevase elukvaliteedi prognoos. Arvesse võetakse ka patsientide tegelikku kliinilist seisundit, nende üldist terviseseisundit, kaasuvaid haigusi ja patsientide soovi. Kuigi on teada, et peamine tegur, mis mõjutab ravi õnnestumist, on kaasuvad ja kroonilised haigused, ja kõrgemat vanust seostatakse statistiliselt sagedamini kaasuvate ja krooniliste haigustega, ei tohi tavalises olukorras ega COVID-19 pandeemia ajal vanuse alusel patsiente diskrimineerida.

Eesti juhistes öeldakse, et ravi andmisel või jätkamisel tuleks arvestada üksnes meditsiinilisi kriteeriume ja patsientide tahet, s.t kas nad üldse soovivad intensiivravi. Eestis ei ole sageli piisavalt tähelepanu pööratud autonoomia põhimõttest lähtuvale patsiendi varasema tahte arvestamisele, kui tehakse intensiivravi otsuseid. Seepärast soovitasime, et patsientidelt tuleks küsida varem, mida nad soovivad juhul, kui olukord läheb kriitiliseks, ennetamaks olukorda, kus teised peavad ära arvama, mida patsient tõeliselt tahtis. Eesti juhised pööravad ka palju tähelepanu hoolimisele ja inimväärikusele. Rõhutatakse, et kui aktiivne ravi katkestatakse, tuleb teha kõik võimalik, et leevendada patsientide kannatusi ning tagada nende inimlik ja hooliv kohtlemine.

Juhised tuletavad arstidele ja haiglatele meelde, et karantiiniaegse külastuskeelu tõttu võivad patsiendid tunda end hüljatud ja üksildasena. Soovitasime haiglatel pakkuda uusi võimalusi, sealhulgas info- ja kommunikatsioonitehnoloogilisi seadmeid, et patsiendid saaksid oma peredega sidet hoida. Soovitasime haiglatel ka võtta tööle rohkem psühholooge, hingehoidjaid ja/või kaplaneid, kes hoolitseksid patsientide ja meditsiinitöötajate vaimse heaolu eest, ning rõhutasime, kui oluline on toetav ja empaatiline suhtlemine patsientide pereliikmetega. Lõpuks tõstsid Eesti juhised esile ka koostöö tähtsust eri haiglate ja nende töötajate vahel. Viimane põhimõte juhistes osutas, et kogu Eesti tervishoiutöötajad ja haiglad peaksid üksteist toetama raskes olukorras ja tegema koostööd, jagades oma teadmisi, oskusi ja ressursse.

\section{Saadud õppetunnid}

COVID-19 epideemia saabus Euroopa eri riikidesse eri aegadel. Eesti sattus õnneks nende riikide hulka, kes said õppida teiste riikide valusast kogemusest. Kuna kaitsemeetmete toime oli tõhus, ei halvenenud olukord Eestis 2020. aasta kevadel nii palju, kui ennustati ja kardeti. Seepärast tekkis küsimus, kas oli üldse mõttekas koostada selliseid drastilisi soovitusi ressursside jaotamiseks COVID-19 pandeemia ajal.

Meie arvates oli selliste juhiste kirjutamine tol ajal oluline (muuhulgas distsiplineeris see inimesi piirangutest kinni pidama), kuna soovituste kirju- 
tamise ajal ei teadnud keegi, kas neid läheb vaja. Meile antud lisaaeg seetõttu, et pandeemia algas varem Lõuna-Euroopas, võimaldas ennetavatel piirangumeetmetel tõhusalt toimima hakata ning kuigi koolid, ülikoolid, teatrid, kinod, spordisaalid ja ostukeskused olid suletud, ei olnud piirangud kordagi karmuselt võrreldavad Itaalia, Prantsusmaa, Hispaania, Suurbritannia omadega. Rangemad meetmed kehtestati Saaremaal, kus oli varakult kõrge nakatumistase. Nõnda oli see mõnes mõttes "hea kriis", mis võimaldas põhjalikult valmistuda kõikidel tasanditel, sealhulgas mõelda läbi piiratud ressursside jaotamise eetilised aspektid. Kuid arutelud juhiste kirjutamise ajal ja peavoolumeedias tõid tervishoiusüsteemis välja mitu fundamentaalset eetilist probleemi, mida tuleb lahendada, olgu kriis või mitte.

Eesti arstid ei pidanud tegelikkuses hakkama täitma rangeid ressursside jaotamise reegleid. Seepärast me ei tea, kas, kuidas ja milliste praktiliste, psühholoogiliste, sotsiaalsete ja õiguslike tagajärgedega oleks utilitaristlikum katastroofimõtlemine välja vahetanud traditsioonilise deontoloogilise lähenemise meditsiinis.

COVID-19 on eriti ohtlik nende elule ja heaolule, kes on juba niigi haavatavad kaasuvate haiguste tõttu ja see on sageli korrelatsioonis vanusega. On hästi teada, et viirus on eriti rängalt tabanud eakaid (Itaalias üle 83\% surnutest olid üle 70aastased, Statista... 2020). Invasiivsete ja intensiivsete intensiivravivõtete kasutamine nendel juhtudel pani muretsema nende kliinilise mõttekuse ja ravi asjatuse pärast: formaalselt võidakse päästa elu, aga selle elu kvaliteet ja selle hoidmise hind võivad olla vastuvõetamatud. Peale selle on paljud sellised rasked kliinilised otsused seotud palliatiivravi kättesaadavuse ja kvaliteediga.

Need mured on lähedalt seotud patsiendi tahte laiema teemaga. Eestis ei ole tavaks täpsustada isiklikult vastuvõetavaid meditsiinilisi sekkumisi ja ravi tahtevalduses. Neid teemasid enamasti ei arutata oma pereliikmetega, veel vähem oma arsti või teiste tervishoiutöötajatega. Kriisihetkel ei pruugi alati olla võimalik täita patsiendi eelistusi meditsiiniliste sekkumiste osas, kuid need võivad siiski aidata otsuseid teha, näiteks kõrvaldades mõne keerulise dilemma (vt McCullough 2020 radikaalsemat vaadet, et patsientide soovid ei peaks mängima mitte mingit rolli ressursside jaotamises katastroofi ajal). Üks pandeemia õppetunde on seega see, et meil tuleb "normaalsetel aegadel" ühiskonnana tegeleda patsientide tahteavalduse teemaga. 2020. aasta sügisel moodustasid Eesti Arstide Liit ja Tartu Ülikooli eetikakeskus töögrupi patsiendi elulõpu tahteavaldusega tegelemiseks.

Pidasime Eesti tervishoiusüsteemi nõrkuseks seda, et palliatiivravi ei ole kättesaadav kõigile, kes seda vajavad. Niisiis olime teadlikud, et isegi kui juhised rõhutavad, et kui aktiivne ravi katkestatakse, tuleb teha kõik võimalik patsientide kannatuste leevendamiseks ning nende inimlikuks ja hoolivaks kohtlemiseks, ei pruugi see alati võimalik olla, kuna ressursse alati ei ole. 
Lõpuks tõi kriis esile, kui olulised on hea kommunikatsiooni reeglid ja tavad, kui meditsiinitöötajad suhtlevad patsientide ja nende peredega. Me nägime vähemalt ühte juhtumit, kus järgiti meie soovitust, et haiglad peaksid pakkuma uusi võimalusi, sealhulgas ITK seadmeid, et patsiendid saaksid hoida oma peredega ühendust - 30 patsienti ühes haiglas said iPadid oma peredega suhtlemiseks.

Ajakirjanike ja poliitikute reaktsioonidest juhiste avaldamisele võib näha, kuidas sellise olukorra ilmnemine ja vajadus teha nii ränki otsuseid oleks avalikkust šokeerinud. Kui meie, kes me vastutasime juhiste eetilise analüüsi eest, osalesime arutelus Riigikogus ja meilt küsiti, kuidas see juhtus, et juhised avalikustati, vastasime, et haiglate eetikakomiteed ei kavatsenud kunagi neid salajas hoida, sest salatsemine teeb inimesed ärevaks. Kuid kriisiolukorras on usaldus meditsiinisüsteemi ja arstide vastu kriitilise tähtsusega.

Me usume, et kriisiolukorra eetiliste valikute läbimõtlemine ja avalikult arutamine edendas koostööd arstide ja eetikute vahel ning aitas selgitada avalikkusele, millised on valikud otsuste taga. Samuti suurendas sellise dokumendi koostamine teadlikkust vajadusest kokku leppida meditsiiniregulatsioonide eetilistes alustes, tõi välja Eesti meditsiinisüsteemi nõrkused ja selgitas teemasid, millega tuleks edasi töötada siis, kui kriis on möödas.

COVID-19 pandeemiaga seotud eetikajuhiste buum maailmas ei ole muidugi möödunud kriitikata. Ehk olulisim etteheide puudutab asjaolu, et enamik juhiseid tegeles küll oluliste väärtuste ning põhimõtete ülekinnitamisega, aga tegelikkuses ei pakkunud konkreetseid lahendusi nii tavapärastele konfliktidele nende väärtuste vahel (Lewis \& Schuklenk 2021). Probleemsena on nähtud ka asjaolu, et sisuliselt poliitikakujundamise dokumendile kleebiti "eetiliste juhtnööride" silt ning enamasti pole selge, kes ja kuidas nende dokumentide väljatöötamisse panustas (Schuklenk \& Savulescu 2021). Seda viimast etteheidet loodab käesolev artikkel küll Eesti näite puhul leevendada.

Samas tõstatavad need etteheited laiema küsimuse taoliste eetikaregulatsioonide rolli ja eesmärkide osas. Kui filosoofilises eetikas on sihiks jõuda tõeni, siis COVID-19 regulatsioonidel olid ka muud funktsioonid - näiteks suurendada otsustuste läbipaistvust, kindlustada, et haavatavad grupid on kaitstud ning signaliseerida ühiskonnale, et need keerulised otsused on vähemalt mingis aspektis läbi kaalutud.

\section{Tänusõnad}

Täname toe eest Eesti-uuringute Tippkeskust (Euroopa Liit, Euroopa Regionaalarengu fond). Oleme väga tänulikud Laura Lilles-Heinsarile ajakirjas Trames ilmunud artikli eestindamise eest. 


\section{Kommentaarid}

1 Artikkel on laiendatud eestikeelne versioon M. Sutropi ja K. Simmi ingliskeelsest artiklist "Developing guidelines for the distribution of scarce medical resources during the COVID-19 pandemic: the Estonian case", mis ilmus ajakirjas Trames 24 (2), 2020.

${ }^{2}$ Kirjavahetus prof dr Joel Starkopfi ja dr Kristo Eriksoniga.

\section{Internetiallikad}

Ammer, Valmar \& Elmet, Katrin \& Erikson, Kristo \& Ginter, Jaan \& Juurik, Marten \& Kudeviita, Merit \& Kõnnussaar, Tiia \& Mahhova, Elena \& Migur, Andra \& Parder, Mari-Liisa \& Remmel, Meego \& Simm, Kadri \& Sutrop, Margit \& Tepp, Jaan 2020. Kliinilise eetika alased soovitused Eesti haiglatele piiratud tervishoiuressursside jaotamiseks COVID-19 pandeemia tingimustes (https://www.regionaalhaigla.ee/sites/ default/files/documents/Eetikaalased_soovitused_A4.pdf - 04.11.2021).

Arstide väärtuste mäng. Tartu Ülikooli eetikaveeb (https://www.eetika.ee/et/ vaartusarendus/arstidele-meditsiinitootajatele - 04.11.2021).

Berlinger, Nancy \& Wynia, Matthew \& Powell, Tia \& Hester, Mmicah \& Milliken, Aimee \& Fabi, Rachel \& Cohn, Felicia \& Guidry-Grimes, Laura K. \& Watson, Jamie Carlin \& Bruce, Lori \& Chuang, Elizabeth J. \& Oei, Grace \& Abbott, Jean \& Jenks; Nancy Piper 2020. Ethical framework for health care institutions responding to Novel Coronavirus for institutional ethics services responding to COVID-19. managing uncertainty, safeguarding communities, guiding practice. The Hastings Centre, 16. märts (https:// www.thehastingscenter.org/ethicalframeworkcovid19/ - 04.11.2021).

BMA 2020 = COVID-19: ethical issues. A guidance note. B[ritish] M[edical] A[ssociation]. Uuendatud 12. mail (https://www.bma.org.uk/advice-and-support/covid-19/ethics/covid19-ethical-issues - 04.11.2021).

DIVI 2020 = Entscheidungen über die Zuteilung von Ressourcen in der Notfall- und der Intensivmedizin im Kontext der COVID-19-Pandemie. Klinisch ethische Empfehlungen der Deutscnen Interdisziplinären Vereinigung für Intensiv- und Notfallmedizin (DIVI), der Deutschen Gesellschaft für Interdisziplinäre Notfall- und Akutmedizing (DGINA), der Deutschen Gesellschaft für Anästhesiologie und Intensivmedizin (DGAI), der Deutsche Gesellschaft für Internistische Intensivmedizin und Notfallmedizin (DGIIN), der Deutsche Gesellschaft für Pneumologie und Beatmungsmedizin (DGP), der Deutschen Gesellschaft für Palliativmedizin (DGP) und der Akademie für Ethik in der Medizin (AEM).. Deutsche Interdisziplinäre Vereinigung für Intensiv- und Notfallmedizin (DIVI) 25.03.2020 (https://www.divi.de/empfehlungen/publikationen/covid-19/1540-covid-19ethik-empfehlung-v2/file - 19.05.2020, enam ei avane).

Deutscher Ethikrat 2020. Solidarity and the responsibility during the Coronavirus crisis: ad hoc recommendation. Deutscher Ethikrat 27. märts. (https://www.ethikrat.org/ fileadmin/Publikationen/Ad-hoc-Empfehlungen/englisch/recommendation-coronaviruscrisis.pdf - 04.11.2021). 
Lübbe, Weyma 2020. Corona-Triage. Ein Kommentar zu den anlässlich der CoronaKrise publizierten Triage-Empfehlungen der italienischen SIAARTI-Mediziner. Vervassungsblog on matters constitutional 15. märts (https://verfassungsblog.de/coronatriage/ - 04.11.2021).

Meyfroidt, Geert \& Vlieghe, Erika \& Biston, Patrick \& De Decker, Koen \& Wittebole, Xavier \& Collin, Vincent \& Depuydt, Pieter \& Nam, Nguyen Duk \& Hermans, Greet \& Jorens, Philippe. \& Ledoux, Didier \& Taccone, Fabio \& Devisch, Ignaas 2020. Ethical principles concerning proportionality of critical care during the 2020 COVID-19 pandemic in Belgium: advice by the Belgian Society of Intensive Care Medicine. Hartcentrum Hasselt, 18. märts (https://www.hartcentrumhasselt.be/professioneel/nieuws-professioneel/ethicalprinciples-concerning-proportionality-of-critical-care-during-the-covid-19-pandemicadvice-by-the-belgian-society-of-ic-medicine - 04.11.2021).

NICE 2020 = COVID-19 rapid guideline: critical care in adults. 2 . märts. National Institute for Health and Care Excellence (https://www.nice.org.uk/guidance/ng159/resources/ covid19-rapid-guideline-critical-care-in-adults-pdf-66141848681413 - 04.11.2021).

Nõmper, Ants 2020. Kriisi süngeim tund arsti jaoks: valik patsientide vahel. Delfi 06. aprill (https://www.delfi.ee/news/paevauudised/eesti/kriisi-sungeim-tund-arsti-jaoksvalik-patsientide-vahel?id=89478639 - 05.11.2021).

Statista Research Department 2020. Coronavirus (COVID-19) death rate in Italy as of May 13, 2020, by age group. Statista Research Department (https://www.statista.com/ statistics/1106372/coronavirusdeath-rate-by-age-group-italy/ - 05.11.2021).

Sutrop, Margit 2020. Margit Sutrop: Soovitused rasketeks valikuteks. Postimees 08. aprill (https://leht.postimees.ee/6944396/margit-sutropsoovitused-rasketeks-valikuteks _ 05.11.2021).

Swiss... 2020 = COVID-19 pandemic: triage for intensive-care treatment under resource scarcity. Swiss Medical Weekly, 24. märts (DOI: 10.4414/smw.2020.20229).

Vergano, Marco \& Bertolini, Guido \& Giannini, Alberto \& Gristina, Giuseppe \& Livigni, Sergio \& Mistraletti, Giovanni \& Petrini, Flavia 2020. Clinical ethics recommendations for the allocation of intensive care treatments in exceptional, resource-limited circumstances. SIIARTI, 16. märts (https://d1c2gz5q23tkk0.cloudfront.net/assets/uploads/3017015/asset/ SIAARTI_-_Covid-19_-_Clinical_Ethics_Reccomendations.pdf?1606745893-05.11.2021).

Österreichische... 2020 = Allokation intensivmedizinischer Ressourcen aus Anlass der Covid-19-Pandemie. Klinisch-ethische Empfehlungen für Beginn, Durchführung und Beendigung von Intensivtherapie bei Covid-19-Patientinnen. Österreichische Gesellschaft für Anesthesiologie, Reanimation und Intensivmedizin, 17. märts (https:// www.oegari.at/web_files/cms_daten/covid-19_ressourcenallokation_gari-statement_ v1.7_final_2020-03-17.pdf-05.11.2021).

\section{Kirjandus}

Ezekiel, J. Emanuel \& Persad, Govind \& Upshur, Ross \& Thome, Beatriz \& Parker, Michael \& Glickman, Aaron \& Zhang, Cathy \& Boyle, Connor \& Smith, Maxwell \& Philips, James P. 2020. Fair allocation of scarce medical resources in the time of Covid-19. The New England Journal of Medicine (DOI: 10.1056/NEJMsb2005114). 
Huxtable, Richard 2020a. COVID-19: where is the national ethical guidance? BMC Medical Ethics 21 (32) (DOI: 10.1186/s12910-020-00478-2).

Huxtable, Richard 2020b. Ethical road map through the covid-19 pandemic. BMJ 2020;369:m2033 (DOI: 10.1136/bmj.m2033).

Häyry, Matti 2020. The COVID-19 pandemic: a month of bioethics in Finland. Cambridge Quarterly of Healthcare Ethics, 20. aprill (DOI: 10.1017/S0963180120000432).

Lewis, Jonathan \& Schuklenk, Udo 2021. Bioethics met its COVID-19 Waterloo: The doctor knows best again. Bioethics 35, lk 3-5 (DOI: 10.1111/BIOE.12840).

McCullough, Laurence B. 2020. In response to COVID-19 pandemic physicians already know what to do. The American Journal of Bioethics 20, lk 9-12 (DOI: 10.1080/15265161.2020.1754100).

Rosenbaum, Lisa 2020. Facing Covid-19 in Italy - ethics, logistics, and therapeutics on the epidemic's front line. The New England Journal of Medicine 382 (20), lk 1873-1875 (DOI: 10.1056/NEJMp2005492).

Schuklenk, Udo \& Savulescu, Julian 2021. The COVID-19 pandemic and what bioethics can and should contribute to health policy development. Bioethics 35, lk 227-228 (DOI: 10.1111/bioe.12855).

Simm, Kadri 2020. Ethical decision-making in humanitarian medicine: how best to prepare? Disaster medicine and public health preparedness 10, lk 499-503 (DOI: 1017/ dmp.2020.85).

Sutrop, Margit 2011a. Changing ethical frameworks: From individual rights to the common good? Cambridge Quarterly of Healthcare Ethics 20 (4), lk 533-545 (DOI: 10.1017/S0963180111000272).

Sutrop, Margit 2011b. How to avoid a dichotomy between autonomy and beneficence? From liberalism to communitarianism and beyond. Journal of Internal Medicine 269 (4), lk 375-379 (DOI: 10.1111/j.1365-2796.2011.02349_2.x).

\section{Summary}

\section{Ethical conflicts during the COVID-19 pandemic}

\section{Margit Sutrop}

Professor of Practical Philosophy

Head of the Chair of Practical Philosophy, University of Tartu

margit.sutrop@ut.ee

\section{Kadri Simm}

Associate Professor of Practical Philosophy, University of Tartu

kadri.simm@ut.ee

Keywords: clinical ethics recommendations for Estonian hospitals, COVID-19 pandemic, ethical choices, ethical guidelines, limited medical resources, vaccination certificate, values 
The COVID-19 pandemic has caused unprecedented interest in ethics, as societies are confronted with difficult ethical choices: life versus economic well-being, individual freedom versus health, free movement of people versus public health. All democratic societies have witnessed disagreements concerning restrictions to the free movement of people, vaccination policies, and distribution of healthcare resources. The adopted policies and formulated guidelines showed that different countries prioritized values differently. Amongst the most challenging ethical debates during the COVID-19 pandemic were attempts to formulate clinical ethical guidelines on how limited medical resources and services ought to be allocated should the need exceed availability. This article provides an overview of the process of compiling the clinical ethics recommendations for Estonian hospitals concerning the allocation of limited healthcare resources during the COVID-19 pandemic. The article describes the stakeholder involvement, engagements with comparable international documents, main internal debates and lessons learned for the future.

Margit Sutrop on eesti filosoof, Academia Europaea akadeemik, Tartu Ülikooli praktilise filosoofia professor ja eetikakeskuse juhataja. Tema peamine uurimisvaldkond on praktiline eetika, sealhulgas bioeetika ja eetika ajalugu, samuti haridusfilosoofia.

Margit Sutrop is Estonian philosopher, member of Academia Europaea, Professor of Practical Philosophy, and Head of the Centre for Ethics at the University of Tartu. Her main research interests lie in the field of practical ethics, bioethics, and the history of ethics as well as the philosophy of education.

margit.sutrop@ut.ee

Kadri Simm on eesti filosoof ja eetikateoreetik, Tartu Ülikooli praktilise filosoofia kaasprofessor. Tema teadustöö on seotud poliitika- ja moraalifilosoofia teemadega, peamised uurimissuunad: eetika, bioeetika, poliitikafilosoofia.

Kadri Simm is Estonian philosopher and theoretician of ethics, Associate Professor of Practical Philosophy at the University of Tartu. Her research is related to the issues of philosophy of politics and morality, and her main research fields are ethics, bioethics, and philosophy of politics.

kadri.simm@ut.ee 